\title{
ETHICAL STANDARDS IN TOURISM
}

\author{
IDRIZKOVACI $^{1} \&$ ALBERTA TAHIRI ${ }^{2}$ \\ ${ }^{I}$ Assistant Professor, Faculty of Applied Sciences, Ferizaj, Kosovo \\ ${ }^{2}$ Assistant Professor, Lecturer at Biznesi College, Prishtina, Kosovo
}

\begin{abstract}
Tourism sector due to its significant growth has been one of the most remarkable economic and social phenomena of the past. However, at the same time, there has been a proportionate and equally well-publicized rise of the potentially negative impacts of the rapidly growing tourism imdustry. Researchers have always been critical about the adverse social and environmental impacts on the industry. Ethical tourism signifies tourism which benefits people and the environment of different destinations. The tourism industry has to put in more responsibility and "professionalism" inorder to protect the "golden goose". The main characteristics of ethical tourism are economic prosperity, social equality, and environmental and cultural protection. Inorder to reinforce ethical tourism, United Nation's World Tourism Organization in 1999, adopted the Global Code of Ethics for Tourism. The purpose of its implementation is the main manner towards ensuring sustainable tourism which brings about benefits for both hosts and visitors(travellers) alike.

KEYWORDS: Tourism, Ethical Tourism, Ethical Standards in Tourism, Principles of Ethical Tourism, Code of Ethics for Tourism, Sustainable Tourism \& Corporate Social Responsibility in Tourism
\end{abstract}

Received: Feb 26, 2018; Accepted: Mar 15, 2018; Published: Apr 04, 2018; Paper Id.: IJEEFUSAPR20184

\section{INTRODUCTION}

The significant growth of tourism industry certainly marks tourism as one of the most eccentric economic and social phenomena of the past century. The tremendous growth of tourism in the past sixty years was emplified from the data of the United Nation's World Tourism Organization (UNWTO). ${ }^{1}$ In 1950, the number of international tourists arrivals was 25 million, when tourism began to emerge as a globe economic sector increasing foreign exchange, income and employment across the world; in 2011, the number of international arrivals amounted to 980 million, with expectations set that it will exceed 1.8 billion persons by 2030. The value of tourism related transactions was estimated at 919 billion american dollars, in 2010. After fuel, chemical and automotive products, tourism is ranked as fourth in the export category.

There has been an increasing geographic spread of tourism to almost all the ends of the globe. Tourism growth has meant the industry now stands for the foremost source of foreign exchange earnings in most countries(UNWTO 2005).

In addition to the economic indicators revealing the progress of the tourism industry, there has been a proportional and equally well-publicized increase in the negative impacts of the growing tourism industry (Archer et al., 2005). Researchers have been judgemental of the adverse social and environmental influence of the industry, ranging from supporting western domination over developing countries through the 'host/guest' relationship (Smith and Brent, 2001), to the visual impacts on the landscape caused by the tourist resorts and the edifice (Hudson, 2000). This has in turn led the tourist industry to exercise more responsibility and "professionalism" so that it could 
protect the "golden goose" mirroring the requirements for greater corporate and social responsibility in other industries. ${ }^{2}$ Corporate social responsibility (CSR) is a specific application of the notion of environmental and social auditing to tourism business practice. The technique is strongly promoted by Fair Trade in Tourism, emerging in the late 1990s out of NGO efforts to create a more equitable international trade system. According to Mowforth and Munt (2003), the tourism industry is well behind other industries in terms of CSR, and the absence of ethical leadership in the tourism industry has been "astounding" . However, responsible tourism is no longer a passing trend but has become a recognized and accepted sector within the industry, as wider consumer market trend towards lifestyle marketing and ethical consumption have spread to tourism (Goodwin and Francis, 2003).

Realizing the fact that tourism industry has to promote their ethical attitude inorder to boost their business as it potentially increases a company's profit, management effectiveness, public image and employee relations (Fleckenstein and Huebsch, 1999; Hudson and Miller, 2005). Yet, although more attention is now being paid to ethics in tourism (Holden, 2003; Kalisch, 2002) there is a very weak foundation of research into tourism ethics studies to date (Fennell, 1999). The outcome is that in tourism the arguments presented for and against CSR are often simple and mostly without any practical evidence. ${ }^{5}$.

Thus, this paper will look into and prove the following thesis related to the development of ethics in tourism:

- Tourist host communities, on the one hand and local professionals on the other so that they get acquainted with each other and respect the tourists who visit them and fing out about their lifestyles, tastes and expectations.

- Tourists and visitors should acquaint themselves even before their departure with the culture of the countries they are planning to visit and also must be aware of the health and security risks involved in any travel outside their usual environment and so that they can take measures to minimize those risks.

- There has been an increasing awareness of the environmental influence on tourism. There is always envrionmental hazards in reaching the destinations by cars, planes, buses or ships. At the destinations the visitors are affected by the infrastructure built to accomadate them.

The paper preparation is based on available relevant literature analysis.

\section{WHAT IS ETHICAL TOURISM?}

Ethical tourism simply means tourism that benefits people and environment of different destinations. It can also provide better income to the families living that area by sourcing products and services locally.

Based on three trends, a brand-new role has emerged for consumers in the tourism : firstly, there is thirst for different and more 'exciting' holidays; secondly, there is a growing understanding of the negative impacts of tourism - its clod-hopping footprints in other people'scommunities, as well as the environment: the deserts, forests, seashores and

\footnotetext{
${ }^{2}$ Holbrook, M. B., (1994): The nature of customer values: an axiology of services in the consumption experience, p. 21.

${ }^{4}$ Brancuşi C., Constanta ENEA (2007): The tourism industry of ethics and tourism, available at: http://www.mnmk.ro/documents/2007/2007-20.pdf, visited on February 2, 2018.

${ }^{5}$ Brancuşi C., Constanta ENEA (2007): The tourism industry of ethics and tourism, available at: http://www.mnmk.ro/documents/2007/2007-20.pdf, visited on February 2, 2018
} 
mountains of the world; and, thirdly, the climate change ${ }^{6}$.

The more sustainable ethical tourism possesses the following main characteristics:

\section{ECONOMIC PROSPERITY}

Tourism industry, a long term competitive business which offer fair pay and conditions for their employees. When the products and services for tourism are sourced locally there is a maximum economic benefit to the local communities. Sustainable tourism should be relevant to every holiday sold and make a difference with their travel for every customers concerned..

\section{SOCIAL EQUALITY}

Sustainability offers great benefits to the customers by keeping special destinations, offering safe and satisfying experiences, having the opportunity to interact with the locals that could truly benefit from the visitors. Sustainable travel and tourism is increasingly becoming popular among the people so as to make positive difference on holidays.

Environmental and social protection: Here it provides incentive and resources for the destinations to preserve the wild life and the natural environment as well as the ancient culture and traditions. The holiday makers helps to conserve energy and the accommodation providers helps in reducing the carbon emission. So that it in a way helps the destinations for the future generations. This is the key element of the ever-growing tourism in influencing the environmental movements at international, national and/or local levels and most importantly it has been noted that this principle has been attracting more and more tourists and travellers from and around the world. Global Code of Ethics for Tourism

For a responsible and sustainable tourism, Global Code of Ethics for Tourism (GCET) is a complete set of principles designed to guide key-players in developing the tourism industry. The government, the travel industry, community and the tourists euqally aim at maximizing the sector's benefits while minimizing the negative impacts on the environment, cultural heritage and societies across the globe. This was adopted in 1999 by the General Assembly of theUNWTO, the document is not legally binding.

The 10 principles of Code's fully cover the economic, social, cultural and environmental factors of travel and tourism:

- Tourism's contribution to mutual understanding and respect between people and the society;

- Tourism as a means for individual and collective fulfillment;

- Tourismas a factor of sustainable development;

- Tourismas a user of the cultural heritage of mankind and contributor to its enhancement;

- Tourism as a beneficial activity for host countries and communities;

- Obligations of stakeholders in tourism development;

- Right to tourism;

\footnotetext{
${ }^{6}$ Holden, A. (2003):In Need of a New Environmental Ethic for Tourism, Annals of Tourism Research 30[1], 94-108.
} 
- $\quad$ Liberty of tourist movements;

- $\quad$ Rights of the workers and entrepreneurs in the tourism industry; and

- Implementation of principles of the Global Code of Ethics for Tourism.

\section{Tourism's Contribution to Mutual Understanding and Respect Between People and Societies}

The foundation of a responsible tourism is to understand and promote the ethical values common to humanity, with an attitude of tolerance and respect for religiousdiversity, philosophical and moral beliefs. Stakeholders in tourism industry and tourists themselves should take into account the social ad cultural; traditions and practices of all people, including those of the minorities and narive people and appreciate their worth.

Tourism activities should not affect the attributes and traditions of the host countries and the regions and must give due respect to their law, practices and customs.

The host communities and the local professionals should get acquainted with the tourists who visit them and must get to know about their lifestyle, taste and expectations. The professionals are educated and trained to contribute hospitality.

It is a great task of the public authorities to provide protection for the tourists and visitors and their belongings and must also pay attention to the safety of foreign tourists owing to their vulnerability. Introduction of specific means of information, prevention, security, insurance and assistance consistent with their needs, must be introduced and facilitated. Any will ful destruction of tourism facilities or of elements of cultural or natural heritage, attacks, assaults, kidnapping or threats against tourists or workers of the industry should be severely condemned and punished with respect to their national law.

While travelling they should refrain from trafficking illicit drugs, arms, antiques, protected species and products and substances that are dangerous or prohibited by national regulations. The tourists and visitors must not commit any criminal act or anything considered criminal by the law of the country visited and abstain from any conduct felt to be offensive or injurious by the local population or sometimes likely to damage the environment.

Even before their departure, the tourists and the visitors must acquaint themselves with the characteristics of the countries they are planning to visit. They must be aware of the risks factors like health and security risks involved in any travel away from their usual environment and must be prepared to minimize those risks.

\section{TOURISM AS A VEHICLE FOR INDIVIDUAL AND COLLECTIVE FULFILLMENT}

Tourism should be planned and practised as a privileged means of individual and collective fulfillment, associated with rest and relaxation, sport and access to culture and nature. Tourism is an irreplaceable factor of entertainment, selfeducation, mutual tolerance and for learning about legal differences between people and their cultural diversity, if practised with an open mind.

Equality of men and women is an important matter in the tourismactivity. Human rights and more particularly, the individual rights of the susceptible groups, notably children, the elderly, the handicapped, ethnic minorities and indigenous people. Exploitation of human beings in any form, particularly sexual, especially when applied to children, contradicts with the fundamental aims of tourism. In accordance with the international law, it must be dynamically battled with the 
cooperation of the states and countries concerned and penalize the perpetrator of such acts without any compromise, by the national legislation of both the countries visited, even when it is carried out abroad. Travelling for the purposes of religion, health, education and cultural linguistic exchanges are meant to be beneficial forms of tourism, that deserve motivation.

The value of tourist exchanges, their economic, social and cultural benefits and also the risk factors should be introduced in the education curriculum.

\section{TOURISM, A FACTOR OF SUSTAINABLE DEVELOPMENT}

With a view to achieving sound, continuous and sustainable economic growth geared to satisfying the needs and aspirations of the present and future generations, the stakeholders in the tourism industry must take care to safeguard the natural environment.

To save rare and precious resources, in particular water and energy, and avoid waste production as much as possible, all forms of tourism development are conducive and should be given priority and encouraged by national, regional and local public authorities.

Uniform distribution of holidays should be sought to reduce the tourism activity pressure on the environment and also to enhance beneficial impact on the tourism industry and the local economy so as .

While designing the tourism infrastructure, it is necessary to ensure the protection of the ecosystems and biodiversity, preserving the endangered wildlife species. Imposition of limitations or constraints on their activities by the stakeholders in tourism development is a must particularly in sensitive areas such as deserts, polar or high mountain regions, coastal areas, tropical forests or wetlands, which are considered essential to the creation of nature reserves or protected areas.

Nature tourism and ecotourism are conducive to enriching and enhancing tourism, provided they respect the natural heritage and local populations and are maintaining the sites' carrying capacity.

\section{Tourism- a User of the Cultural Heritage of Mankind and Contributor to its Enhancement}

As we are all aware, tourism is a resource that belongs to the common heritage of mankind. In territories that possess these resources, the communities have particular rights and obligations to protect these resources.

With regard to the artistic, archaeological and cultural heritage, it is necessary to conduct tourism policies and activities, so that these heritages are passed on to future generations. Preserving and upgrading monuments, shrines and museums as well as archaeological and historic sites are very essential and must be widely open to tourist visits. Public access to privately owned cultural property and monuments should be encouraged, regard to not only withthe rights of their owners but also religious buildings, without prejudice to normal needs of worship.

Visits to cultural sites and monuments resulted in financial resources, which should be used for maintaining, safeguarding, developing and embellishing the heritage.

For survival and flourishing of traditional cultural products, crafts and folklore, it is necessary to plan the tourism activities, instead of allowing them to degenerate.

\section{TOURISM- A BENEFICIAL ACTIVITY FOR HOST COUNTRIES AND COMMUNITIES}

Through tourism, the local populations can obtain jobs, which are associated with tourism, raising their standard 
of living. This can be achieved through various tourism policies. Operation of tourism resorts should aim to integrate planning and architectural approachwith the local economic.

Tourism can often be considered an atypical opportunity for development of traditional economic activities which is on a declining trend.

Before implementing their projects, tourism professionals and investors (regulated by the regulations laid down by the public authorities), with the greatest transparency and objectivity, should understand the impact of their various development projects on the environment and natural surroundings; they should also provide complete information on their future programmes and their foreseeable impact and encourage dialogue on their contents with the populations concerned.

\section{OBLIGATIONS OF STAKEHOLDERS IN TOURISM DEVELOPMENT}

The obligation of tourism professionals is to provide tourists with correct and honest information regarding their tourist destination and also on the travel conditions, hospitality and stays. They should also ensure that the contractual clauses proposed to their customers are readily understandable, especially with regard to the nature, price and quality of the services they commit and the financial compensation payable by them in the event of a unilateral breach of contract on their part.

In so far as it depends on them, tourism professionals should take up the responsibility and show concern, along with the public authorities, for the security and safety, accident prevention, health protection and food safety of those who seek their services. Likewise, the existence of suitable systems of insurance and assistance needs to be ensured, acceptance of reporting obligations as indicated by national regulations, and paying fair compensation in the event of failure to fulfill their contractual obligations.

The cultural and spiritual fulfilment of tourists and allowing the tourists to practice their religions all depends on the tourism professionals.

The public authorities of the generating states and the host countries should ensure necessary precautions are taken for the tourists in the event of the bankruptcy of the enterprise responsible for their travel.

It is the responsibility of governments who have the right to inform their nationals/tourists of the difficult circumstances or even the dangers they may encounter during their travels abroad and also to provide such information without prejudicing the tourism industry of the host countries and the interests of their own operators. The contents of travel advisories should therefore be discussed beforehand with the authorities of the host countries and the professionals concerned. Recommendations formulated should be strictly proportionate to the gravity of the situations encountered and confined to the geographical areas where there is insecurity; and these advisories are to be updated or cancelled once there is a return to normality.

Correct, accurate and balanced information on events and situations will surely influence the flow of tourists. This can be achieved by the press, particularly the specialized travel press and the other media including the modern means of electronic communication. Consumers of tourism services required to be provided with accurate and reliable information. By doing this, the media should not in any manner promote sex tourism. 


\section{RIGHT TO TOURISM}

For the world's inhabitants, the prospect of direct and personal access to the discovery and enjoyment of the planet's resources should constitute a right equally open to all. One of the best possible expressions of the continued and stable growth of free time is the increasingly extensive participation in national and international tourism, with no obstacles in its way.

The corollary of the right to rest and leisure is the universal right to tourism, including reasonable limitation of working hours and periodic holidays with pay, which in turn are guaranteed by Article 24 of the Universal Declaration of Human Rights and Article 7.d of the International Covenant on Economic, Social and Cultural Rights.

With the support of the public authorities, it is important to develop social tourism and, in particular associative tourism, which facilitates widespread access to leisure, travel, and holidays.

It is absolutely required to encourage and facilitate family, youth, student and senior tourism and tourism for people with disabilities.

\section{LIBERTY OF TOURIST MOVEMENTS}

In accordance with international law and national legislation and Article 13 of the Universal Declaration of Human Rights, tourists and visitors should benefit from the liberty to move within their countries and from one state to another. Without being subjected to excessive formalities or discrimination, tourists should have access to places of transit and stay and to tourism and cultural sites.

Tourists and visitors should have prompt and easy access to local administrative, legal and health services and to all available forms of communication, internal or external. In accordance with the diplomatic conventions in force, the tourist should be free to contact the consular representatives of their countries of origin.

The rights of tourists should be the same as the citizens of the country visited, with regard to the confidentiality of the personal data and information.

It is necessary to adapt administrative procedures with regard to border crossings, , such as visas or health and customs formalities, especially whether the procedures fall within the competence of states or result from international agreements, so that maximum freedom of travel and widespread access to international tourism are ensured. Therefore, it is essential to encourage agreements between countries so that these procedures are harmonized and simplified. It is also a must to correct specific taxes and levies penalizing the tourism industry and undermining its competitiveness.

Travelers should be enabled to allowances of convertible currencies needed for their travels, based on the economic situation of the countries from which they come.

\section{RIGHTS OF THE WORKERS AND ENTREPRENEURS IN THE TOURISM INDUSTRY}

In the tourism and related industries, under the supervision of the national and local administrations, it is necessary to guarantee the fundamental rights of salaried and self-employed workers, with regard to their states of origin and the host countries, given the specific constraints linked to the seasonality of their activity, the global dimension of their industry and the flexibility often required of them based on their nature of work.

In the tourism and related industries, both salaried and self-employed workers have the right and the duty to 
acquire appropriate initial and continuous training and should also be given adequate social protection, limiting job insecurity. Regarding their social welfare, specific status should be offered to seasonal workers in the sector.

In the field of tourism, under the existing national laws, any natural or legal person with the necessary abilities and skills should be entitled to develop a professional activity. In the area of small- and medium-sized enterprises, it is a must that entrepreneurs and investors are entitled to free access to the tourism sector, with a minimum of legal or administrative restrictions.

Executives and workers from different countries should exchange their experiences, encouraging the world tourism industry development. These movements should be in compliance with the national laws and international conventions applicable.

In the development and dynamic growth of international exchanges, multinational enterprises of the tourism industry should not exploit the dominant positions they occupy. They should avoid becoming the vehicles of cultural and social models artificially imposed on the host communities. In exchange for their freedom to invest and trade which are fully recognized, they should involve themselves in local development by the excessive repatriation of their profits or their induced imports, avoiding a reduction in their contribution to the economies.

Establishing balanced relations between enterprises of generating and receiving countries play an important role in the maintainable development of tourism and an equitable distribution of the benefits of its growth.

\section{Implementation of the Principles of the Global Code of Ethics for Tourism}

For tourism development, it is essential that the public and private stakeholders cooperate and also monitor the implementation and application of these principles.

With regard for the general principles of international law, in tourism development, the stakeholders should monitor the role of international institutions (UNWTO ranked first) and non-governmental organizations with competence in the field of tourism promotion and development, and the protection of human rights, the environment or health, thereby referring for conciliation to an impartial body known as the World Committee on Tourism Ethics any disputes concerning the application or interpretation of the Global Code of Ethics for Tourism.

\section{CONCLUSIONS}

Although codes, policies, and principals are very important and useful, they do not cover every situation, often conflict, and require considerable interpretation. Researchers will have to learn to interpret, assess, and apply various rules, make decisions and act in various situations; and the vast majority of decisions include straightforward application of ethical rules.

Primarily it is necessary to train and educate all stakeholders of tourism industry, concerning the Global Code of Ethics for Tourism, wherein the states and governments play a chief role and ensure international coordination, exchange and cooperation.

Apart from training and education, states and governments need to focus on the implementation of the Global Code of Ethics for Tourism and also develop participatory implementation mechanisms. To ensure that authorities' responses to the code remain coherent, effective, and efficient, public policies are to be in place, and monitoring 
mechanisms are to be established and operational. Awareness raising activities need to target the public at large.

All these will ensure tourism benefits both the hosts and the visitors, securing the sustainability and longevity of attractive tourist destinations. Thus the tourist industry can maintain its rapid development and progress, thereby increasing its contribution to the overall well-being of the countries across the globe.

\section{REFERENCES}

1. Holbrook, M. B., (1994): The nature of customer values: an axiology of services in the consumption experience, p. 21

2. Parasuraman, A., Zeithaml, V. A., Berry, L. L., (1985): A conceptual model of service quality and its implications for uture research, Journal of Marketing, 49, 41- 50

3. Holden, A. (2003): In Need of a New Environmental Ethic for Tourism, Annals of Tourism Research 30[1], 94-108.

4. Archer, B., C. Cooper and L. Ruhanen (2005): The Positive and Negative Impacts of Tourism, in W.F.

5. Fennell, D. (1999). Ecotourism: An Introduction [Routledge, London]

6. Goodwin, H. and J. Francis (2003): Ethical and Responsible Tourism: Consumer Trends in the UK, Journal of Vacation Marketing 9[3], 271-282

7. Holden, A. (2003): In Need of a New Environmental Ethic for Tourism, Annals of Tourism Research 30[1], 94-108

8. Hudson, S. and G. Miller (2005): The Responsible Marketing of Tourism: The Case of Canadian Mountain Holidays, Tourism Management 26[2], 133-142

9. Ingbar J. (2004). From Organizational Ethics: Where Values and Culture Meet; Institute for Global,Camden, ME

10. Institute for Global Ethics, (2006). Ethical Fitness for a Better World, Annual Report

11. United Nations World Tourism Organization, Tourism Market Trends available at: http://cf.cdn.unwto.org/sites/all/files/docpdf/markettrends.pdf, visited on February 2, 2018

12. Brancuşi C., Constanta ENEA (2007): The tourism industry of ethics and tourism, available at: http://www.mnmk.ro/documents/2007/2007-20.pdf, visited on February 2, 2018

13. World Tourism Organization: Global Code of Ethics for Tourism, available on: http://ethics.unwto.org/en/content/globalcode-ethics-tourism, visited on February 2, 2018 
